\title{
The Effect of Pricing Strategy on Home Selection and Transaction Prices: An Investigation of the Left-Most Digit Effect
}

Eli Beracha and Michael J. Seiler

\section{Abstract}

In this study, we examine whether homebuyers favor homes associated with just below pricing strategies or those with rounded prices (e.g., \$199,900 vs. \$200,000). The inclination for just below pricing allows sellers that use just below pricing to set a higher asking price without driving away potential buyers. Rounded priced homes, on the other hand, sell significantly faster and at a smaller discount from list price compared with just below priced homes. We find that the just below pricing strategy yields the highest transaction price relative to the true underlying home value. This suggests sellers exploit buyers' preference for just below priced homes with a higher initial listing price that outweighs the lower discount and shorter time on market associated with similar round priced homes, making just below pricing the more effective pricing strategy.

Estimating the fair market value of residential real estate is an inexact science, so real estate agents continually debate whether it is best to set the list price of a home at a rounded off number, like $\$ 200,000$, or set it just below at $\$ 199,900$. Proponents of the "just below" pricing strategy maintain that while everyone has the mental capacity to round up the just below price of $\$ 199,900$ to $\$ 200,000$ and properly see the two prices as effectively equal, homebuyers looking at many different properties in a relatively short period of time will rely on the price truncation heuristic. Price truncation is a phenomenon that describes how the human brain processes our reading of a multi-digit number. As explained in Dehaene (1997), the human brain works so quickly that before we even finish reading the number, on a subconscious level, our brain has already started to store the left-most digit. Since the numbers to the right are psychologically less meaningful, our brains place less emphasis on remembering the value of these digits. If asked to recall a single number in the short run, people have no problem recalling the number exactly. But, if shown many numbers in a short period of time, people reach a cognitive limit and rely on the heuristic of price truncation. That is, their brain is more easily able to recall the numbers that were given the greatest priority (i.e., the left-most digit).

Proponents of the rounded off pricing strategy support their contention using the more economically based "demand effect." While real estate firms in our sample primarily pull property listings from the same regional Multiple Listing Service (MLS), each brokerage firm creates their own platform that allows clients to search for potential homes. When 
a client searches for homes in the $\$ 150,000-\$ 200,000$ price range, both homes listed for $\$ 199,900$ and $\$ 200,000$ appear in the search results. However, the home priced at $\$ 200,000$ will also appear in a search ranging from \$200,000-\$250,000, whereas the home priced at $\$ 199,900$ will not. As such, if the agent prices the home using a rounded list price, she will increase the exposure of the listing to potential buyers. ${ }^{1}$

A second and potentially greater benefit to rounded pricing is that it is typical for the results from a home search query to be sorted by price. Listing a home at a rounded number like $\$ 200,000$ means the property will be the first home that buyers see when viewing the search results. ${ }^{2}$ Importantly, Seiler, Madhavan, and Liechty (2012) document that buyers spend more than twice as much time looking at the first home that comes up in the search and that the homebuyer's time spent examining subsequent homes diminishes rapidly thereafter. In sum, agents who support rounded pricing cite the increase in demand that will result from greater property exposure in that the home will appear in a greater number of searches and also earlier within the search results. Basic economics would suggest that an increase in demand should result in an increased equilibrium or transaction price.

The purpose of this study is to examine whether the just below "pricing effect" exists, and if it does, how does its strength compare to the rounded price-based "demand effect"? Settling the debate between whether it is better to list homes at rounded or just below prices can be accomplished by observing the final transaction price and the time on the market (TOM) necessary to sell the property. However, drivers of psychological pricing effects cannot be inferred from final transaction prices. We care more in this study about the $w h y$, not just the what. For example, transactions data only records the listing and final selling price of the home. It does not hold all other variables in the market constant and allow the researcher to isolate specific pricing attributes of the home one at a time. Only a controlled experiment can do this. As such, we begin our investigation by performing a pricing experiment where actual homeowners are shown two properties, one with a rounded price and one with a just below pricing strategy. By randomizing the photo, property description, price, and listing order between subjects, we are able to isolate the effect of pricing strategy on home selection preference.

We find that homebuyers slightly prefer the just below priced properties when lowering the price changes the left-most digit (e.g., when pricing between $\$ 200,000$ and $\$ \mathbf{1 9 9}, 900)$. However, this effect fades away when lowering the price by the exact same amount changes the second to the left-most digit (e.g., when pricing between $\$ 190,000$ and $\$ 189,900$ ) or the third to the left-most digit (e.g., when pricing between $\$ 192,000$ and \$191,900). This left-most pricing effect is consistent with a growing financial literature (Bhattacharya, Holden and Jacobsen, 2012). Further robustness tests reveal that if agents are going to engage in just below pricing strategies, they will be more effective at prices ending in 900 or 000 (e.g., $\$ 199,900$ or $\$ 199,000$ ) as opposed to prices that end in 999 or 990 (e.g., \$199,999 or \$199,990).

In an examination of transaction prices and TOM, we find that while the just below pricing strategy does initially attract homebuyers to homes that appeared to be priced lower, the demand effect associated with round priced homes yields lower negotiated discounts relative to the asking price and shorter TOM compared with just below priced 
homes. In order to measure the net effect of the benefits from the two pricing strategies, we conduct an empirical analysis in which we consider the initial degree of overpricing, price discount, and TOM, simultaneously. The results reveal that the just below pricing strategy yields the highest transaction price relative to true underlying home value when TOM is considered. This suggests that sellers' ability to set higher listing prices for properties using a just below pricing strategy outweighs the lower discount and the shorter TOM associated with similar round priced homes. ${ }^{3}$

In sum, we are the first to look beyond transactions data to gain a deeper understanding of the effects underpinning the home selection process. We are also the first to differentiate the effectiveness of the just below pricing strategy based on whether or not the pricing change alters the left-most digit or one further to the right. This level of insight was made possible by the merging of traditional transaction-based pricing data with a carefully crafted experimental design.

\section{Literature Review}

The just below pricing strategy is widely practiced by almost all retailers virtually across the entire globe. In fact, Holdershaw, Gendall, and Garland (1997) documented that 60\% of all prices end in a "9," while only $7 \%$ end with a " $0 ., 4$ The most common example of just below pricing is retail gasoline, which almost always ends in 9/10 of a cent. The fact that the United States has no actual currency this small in denomination demonstrates the observation that just below pricing can be taken to the extreme. ${ }^{5}$ While the origins of just below pricing are debated, there is no denying its impact on retail pricing.

Supporting the continued use of the just below pricing strategy are researchers who find that just below prices result in greater sales volume than rounded priced goods (Schindler and Kibarian, 1996; Gendall, Holdershaw, and Garland, 1997; Stiving and Winer, 1997). Still, most of the research on just below pricing is found in the marketing literature, where the cost of the good is low and the item constitutes a low involvement purchase (e.g., socks, toothbrush, etc.). In these markets, buyers are price takers paying whatever the price tag indicates. Residential real estate markets, however, are very different. Specifically, prices and purchase involvement are high, and list prices are negotiable. As such, it is important to test just below pricing strategies in a real estate-specific context. Only four papers have done so to date. Allen and Dare (2004) examined prices in the south Florida market and found that what they call "charm pricing" leads to higher final sales prices. The opposite result was found by Palmon, Smith, and Sopranzetti (2004), who examined Texas residential real estate prices. Allen and Dare (2006) conducted a follow-up study to add clarity to this stream of research by focusing on the signal charm pricing sends in terms of the firmness of the seller's position. Finally, Salter, Johnson and Spurlin (2007) concluded that off-dollar pricing does not affect selling price, but yields a shorter TOM. Given the mixed findings of these studies, we argue in favor of the need to examine this issue in much greater detail.

\section{The Left-Most Digit Effect}

Thomas and Morwitz (2005) discuss how just below pricing is most effective when the left-most digit in the price changes when going from a rounded to a just below price 
level (e.g., \$4.00 vs. \$3.99). Dehaene (1997) posits the notion that when we read a number our brains are so quick that we start to encode the values into our memory even before we finish reading all the digits. Since we read from left to right, we mentally anchor on the first digit we see (the left-most digit). Given a price of \$3.97, Dehaene argues that we are far more likely to remember the number " 3 " than we are to remember either the "9" or the "7." If all we remember from the price is the " 3 ," we are more likely to think of (recall) the price of the item as $\$ 3.00$ than $\$ 4.00$ (a much more accurate rounding of the true price). As such, a just below pricing strategy that changes the leftmost digit will result in people recalling the price difference between the two assets as being much further apart than a just below pricing strategy that only changes the second to the left-most digit (e.g., \$3.30 vs. \$3.27).

In a financial context, Bhattacharya, Holden, and Jacobsen (2012) found that professional stock traders also form cognitive reference points when stocks cross a price threshold of an even dollar amount. In their examination of over 100 million equity trades, the authors found excessive selling at all price points one cent above round numbers and excessive buying at one penny below. For example, a change in stock price from $\$ 9.00$ to $\$ 8.99$ triggered significantly more buys than a change in price from $\$ 9.07$ to $\$ 9.06$. We explicitly test for the left-most digit effect in both our experimental sample, as well as our transactions-based sample.

\section{Experimental Design}

In order to isolate the effect of pricing strategy on home selection preference, we used a standard between-subjects experimental design. Specifically, we presented each homebuyer with side-by-side property listings where each listing was associated with a photo, property description, and price (just below vs. rounded). We then asked the homebuyer to select the home they would prefer to buy. Between subjects, we randomized the photo, property description, price, and listing order within the experiment. This is a standard design technique employed to remove any unintended influences on the homebuyer's selection preference while still providing a true to life property listing. By effectively altering only the pricing strategy between trials, we attribute homebuyer selection preference to this singly changed variable. ${ }^{6}$ Experimental data were collected using the existing network of homebuyers as fully described in Seiler and Seiler (2010), Seiler, Seiler, and Lane (2012), Seiler, Seiler, Lane, and Harrison (2012), Seiler, Seiler, Harrison, and Lane (2013), Seiler (2014 a,b), Seiler, Lane, and Harrison (2014), and Seiler (2015). In all, 1,000 homebuyers across the state of Virginia ${ }^{7}$ participated in the experiment, resulting in 908 usable and complete responses.

To test the left-most digit effect, it was necessary to also create a second and third variation of the experiment where the just below pricing strategy caused the second (e.g., \$190,000 vs. \$189,900) and third (\$192,000 vs. \$191,900) to the left-most digit to change. Finally, because there are several common variations of the just below pricing strategy, we also considered four just below prices to correspond with our three rounded prices. ${ }^{8}$ The result is an experiment with 12 ( 3 round prices $\mathrm{x} 4$ just below prices) total variants. 
Even in an innocuous revealed preference experiment such as ours, avoiding the introduction of bias is best accomplished when the subjects do not know the true purpose of the study. As such, we followed a standard experimental design protocol and simply shared with participants that we are "conducting a study of the residential real estate market, and that all responses will remain anonymous."

\section{Empirical Analysis}

Transactions data were collected from all sales made in the Hampton Roads, Virginia Metropolitan Statistical Area (MSA) from January 1993 through September 2011. In all, there were 372,074 total residential real estate listings. Of those, 9,131 sales had a listing price that exactly corresponded with the experimental listing prices examined in our study. Unsold or relisted properties are excluded from our analysis. When we examine the probability of sale conditioned on the pricing strategy, we find that $61.33 \%$ of the housing in our sample that were listed using a round pricing strategy sold without being relisted compared with $60.94 \%$ of the housing that were listed using a just below strategy. These selling probabilities are statistically indistinguishable even at the $10 \%$ level. Therefore, the exclusion of these listings from our dataset is unlikely to affect our results.

For analysis and reporting purposes, we denote TOM in months while keeping the daylevel precision that is provided in the data. ${ }^{9}$ We employ a hazard model for TOM with a Weibull distribution. ${ }^{10}$ In our hazard model we include the physical characteristics of the property, as well as the property's degree of overpricing and a dummy variable that indicates the price strategy associated with each property. The pricing discount is defined as the percentage difference between the asking price and the final transaction price. A positive (negative) discount value indicates that a particular property sold for a price below (above) its listing price.

In order to examine the degree of overpricing reflected in the listing price, we employ a two-stage least squares (2SLS) regression where we control for possible simultaneity between the TOM variable and the selling price. Using a randomized half of the dataset, we estimate the following regression where TOM is instrumented simultaneously using the same housing characteristics: ${ }^{11}$

$$
\begin{aligned}
\ln (\text { price }) & =\alpha_{0}+\alpha_{1} * \ln (\text { sqft })+\alpha_{2} * \ln (\text { age })+\alpha_{3} * \text { bedroom }+\alpha_{4} * \text { bath } \\
& +\alpha_{5} * \text { balfbath }+\alpha_{6} * \text { TOM }+\beta_{i} * \sum_{i=1994}^{2011} \text { dumyear_ } i+\varepsilon
\end{aligned}
$$

We then apply the coefficients from equation (1) to the other half of our dataset and define these estimations as the approximate value of each property. Finally, in order to arrive at the initial degree of over pricing (DOP) and transaction price premium (TPP), we divide the listing price and the selling price, respectively, by the estimated property value: 
Exhibit 1. Experimental Results: First, Second, and Third Left-Most Digit and Nines Effects for the Full Sample

\begin{tabular}{|c|c|c|c|c|c|}
\hline & Obs. & $\begin{array}{l}\text { Selected } \\
\text { Just Below }\end{array}$ & $\begin{array}{l}\text { Selected } \\
\text { Rounded }\end{array}$ & Ratio & Sig. \\
\hline \multicolumn{6}{|c|}{ First Left-most Digit Effect } \\
\hline$\$ 200,000$ & 277 & 149 & 128 & $53.8 \%$ & 0.208 \\
\hline$\$ 199,999$ & 63 & 33 & 30 & $52.3 \%$ & 0.709 \\
\hline$\$ 199,990$ & 71 & 38 & 33 & $53.5 \%$ & 0.557 \\
\hline$\$ 199,900$ & 72 & 41 & 31 & $56.9 \%$ & 0.241 \\
\hline$\$ 199,000$ & 71 & 37 & 34 & $52.1 \%$ & 0.725 \\
\hline \multicolumn{6}{|c|}{ Second Left-most Digit Effect } \\
\hline$\$ 190,000$ & 319 & 157 & 162 & $49.2 \%$ & 0.780 \\
\hline$\$ 189,999$ & 81 & 39 & 42 & $48.1 \%$ & 0.741 \\
\hline$\$ 189,990$ & 78 & 27 & 51 & $34.6 \%$ & $0.006 * * *$ \\
\hline$\$ 189,900$ & 82 & 49 & 33 & $59.8 \%$ & $0.077^{*}$ \\
\hline$\$ 189,000$ & 78 & 42 & 36 & $53.8 \%$ & 0.500 \\
\hline \multicolumn{6}{|c|}{ Third Left-most Digit Effect } \\
\hline$\$ 192,000$ & 312 & 156 & 156 & $50.0 \%$ & 1.000 \\
\hline$\$ 191,999$ & 82 & 40 & 42 & $48.8 \%$ & 0.827 \\
\hline$\$ 191,990$ & 78 & 37 & 41 & $47.4 \%$ & 0.654 \\
\hline$\$ 191,900$ & 70 & 36 & 34 & $51.4 \%$ & 0.813 \\
\hline$\$ 191,000$ & 82 & 43 & 39 & $52.4 \%$ & 0.661 \\
\hline Nines Effect & 908 & & & & \\
\hline Price ending in 999 & 226 & 112 & 114 & $49.6 \%$ & 0.895 \\
\hline Price ending in 990 & 227 & 102 & 125 & $44.9 \%$ & 0.127 \\
\hline Price ending in 900 & 224 & 126 & 98 & $56.3 \%$ & $0.061^{*}$ \\
\hline Price ending in 000 & 231 & 122 & 109 & $52.8 \%$ & 0.394 \\
\hline $999 \& 990$ & 453 & 214 & 239 & $47.2 \%$ & 0.241 \\
\hline $900 \& 000$ & 455 & 248 & 207 & $54.5 \%$ & $0.054^{*}$ \\
\hline
\end{tabular}

Notes: This exhibit reports the frequency with which homebuyers selected the Just Below priced home versus the Rounded priced home for all combinations of prices. Statistical significance is based on a onesample $t$-test.

* Significance at $90 \%$.

** Significance at $95 \%$.

*** Significance at $99 \%$.

$$
\begin{aligned}
& D^{D O P} P_{i}=\frac{\text { listing }_{i}}{\text { value }_{i}}-1 . \\
& \operatorname{TPP}_{i}=\frac{\text { selling }_{i}}{\text { value }_{i}}-1 .
\end{aligned}
$$

\section{Results}

Exhibit 1 reports the results. In all, there were 12 pairs of prices examined in the study. The first four pairs result in a change in the left-most digit (\$200,000 vs. \$199,999; $\$ 200,000$ vs. \$199,990; \$200,000 vs. \$199,900; and \$200,000 vs. \$199,000). Recall that price truncation theory suggests just below pricing resulting in a reduction of the leftmost digit should be the most effective at lowering the perceived price in the minds of 
buyers. The exhibit reveals that just below pricing results in a preference for that home in 149 cases, whereas the rounded price of $\$ 200,000$ was selected in just 128 cases. In fact, a slight preference for just below pricing exists for all variations of the just below price.

Exhibit 1 also shows that when the second $(\$ 190,000$ vs. $\$ 189,999 ; \$ 190,000$ vs. $\$ 189,990 ; \$ 190,000$ vs. $\$ 189,900$; and $\$ 190,000$ vs. $\$ 189,000)$ or third $(\$ 192,000$ vs. $\$ 191,999 ; \$ 192,000$ vs. $\$ 191,990 ; \$ 192,000$ vs. $\$ 191,900$; and $\$ 192,000$ vs. $\$ 191,000)$ to the left-most digit is changed, the aggregated preference for just below pricing immediately and completely disappears, as reflected in a $49.2 \%$ (second digit) and $50.0 \%$ (third digit) selection. Unlike the left-most digit effect, which reveals a consistent, albeit moderate, preference for just below pricing strategies at all pricing variants, when changing the second and third left-most digit, participants have a preference for price variants ending in either 900 or 000 (as opposed to either 999 or 990). Interestingly, real estate agents overwhelmingly list prices at these two, more favorable, pricing levels (900 and 000). ${ }^{12}$

To learn why homebuyers might prefer just below pricing strategies that affect only the left-most digit changes, we turn to the literature on perceived price differences. It has been suggested that just below pricing strategies affect the perceived differences between the two prices depending on whether the rounded price changes the left-most digit versus a digit further to the right. One compelling reason for investigating real estate listing prices is that extant studies examining this question exist almost exclusively in the marketing literature where prices of items are typically very low and relate to lowinvolvement purchases (e.g., pens, gum, or apparel). When a high-involvement purchase like residential real estate is considered, do the same results hold? The increased number of total pricing digits that must be processed is reason enough to warrant an investigation.

We investigate the "misperceived price difference" phenomenon to learn if it exists in residential real estate pricing as well. Recall that participants were shown two side-byside property listings, one containing a rounded list price and the other containing a just below price. After the respondent finished examining the listings and selected the home they preferred, the screen advanced and they were not able to backtrack and return to the listing. After advancing the screen, the buyer was asked to recall the exact price difference between the two homes. Note that at no time during the experiment were the participants alerted to the true purpose of our study, nor were they forewarned that they should recall any specific aspect of the listing.

In Exhibit 2, the "Digit $=1$ " column presents results for the experimental trials where the left-most digit changed. The "Digit $=2$ " column presents results where the second to the left-most digit changed, and so forth. "Nines $=3$ " refers to the list price that ends with three nines (999). "Nines $=2$ " refers to prices that ended in 990, and so forth. In the exhibit, the actual/true difference in prices goes from $\$ 1(\$ 200,000-\$ 199,999)$ to $\$ 10(\$ 200,000-\$ 199,990)$ to $\$ 100(\$ 200,000-\$ 199,900)$ and finally to $\$ 1,000(\$ 200,000-$ $\$ 199,000) .^{13}$

As seen in Exhibit 2, 42.3\% of all participants correctly recalled the exact price difference between the rounded and just below priced homes. ${ }^{14}$ When the participants incorrectly guessed the price difference, they significantly over-estimated the difference at more than 
Exhibit 2. Perceived versus Actual Listing Price Differences

\begin{tabular}{|c|c|c|c|c|c|c|c|c|c|c|c|}
\hline & $\begin{array}{l}\text { Price } \\
\text { Difference }\end{array}$ & & Digit = 1 & Obs. & Digit = 2 & Obs. & Digit $=3$ & Obs. & All Digits & Obs. & Chi-Square \\
\hline $\begin{array}{l}\text { Nines = } 3 \\
(999)\end{array}$ & $\$ 1$ & $\begin{array}{l}\text { Under-estimate } \\
\text { Correct } \\
\text { Over-estimate } \\
\text { Chi-Square Test }\end{array}$ & $\begin{array}{r}0.0 \% \\
39.7 \% \\
60.3 \% \\
2.68\end{array}$ & $\begin{array}{r}0 \\
25 \\
38\end{array}$ & $\begin{array}{l}1.3 \% \\
42.3 \% \\
56.4 \% \\
38.39 * * *\end{array}$ & $\begin{array}{r}1 \\
33 \\
44\end{array}$ & $\begin{array}{l}1.3 \% \\
32.9 \% \\
65.8 \% \\
49.39 * * *\end{array}$ & $\begin{array}{r}1 \\
26 \\
52\end{array}$ & $\begin{array}{r}0.9 \% \\
38.2 \% \\
60.9 \%\end{array}$ & $\begin{array}{r}2 \\
84 \\
134\end{array}$ & $121.13^{* * *}$ \\
\hline $\begin{array}{l}\text { Nines }=2 \\
(990)\end{array}$ & $\$ 10$ & $\begin{array}{l}\text { Under-estimate } \\
\text { Correct } \\
\text { Over-estimate } \\
\text { Chi-Square Test }\end{array}$ & $\begin{array}{l}21.4 \% \\
17.1 \% \\
61.4 \% \\
25.06 * * *\end{array}$ & $\begin{array}{l}15 \\
12 \\
43\end{array}$ & $\begin{array}{l}5.2 \% \\
26.0 \% \\
68.8 \% \\
48.65^{* * *}\end{array}$ & $\begin{array}{r}4 \\
20 \\
53\end{array}$ & $\begin{array}{l}5.2 \% \\
15.6 \% \\
79.2 \% \\
74.21 * * *\end{array}$ & $\begin{array}{r}4 \\
1 \\
61\end{array}$ & $\begin{array}{l}10.3 \% \\
19.6 \% \\
70.1 \%\end{array}$ & $\begin{array}{r}23 \\
44 \\
157\end{array}$ & $139.13^{* * *}$ \\
\hline $\begin{array}{l}\text { Nines }=1 \\
(900)\end{array}$ & $\$ 100$ & $\begin{array}{l}\text { Under-estimate } \\
\text { Correct } \\
\text { Over-estimate } \\
\text { Chi-Square Test }\end{array}$ & $\begin{array}{l}14.1 \% \\
53.5 \% \\
32.4 \% \\
16.59 * * *\end{array}$ & $\begin{array}{l}10 \\
38 \\
23\end{array}$ & $\begin{array}{l}4.9 \% \\
32.1 \% \\
63.0 \% \\
40.96^{* * *}\end{array}$ & $\begin{array}{r}4 \\
26 \\
51\end{array}$ & $\begin{array}{l}7.1 \% \\
38.6 \% \\
54.3 \% \\
24.20 * * *\end{array}$ & $\begin{array}{r}5 \\
27 \\
38\end{array}$ & $\begin{array}{r}8.6 \% \\
41.0 \% \\
50.5 \%\end{array}$ & $\begin{array}{r}19 \\
91 \\
112\end{array}$ & $64.30 * * *$ \\
\hline $\begin{array}{l}\text { Nines }=0 \\
(000)\end{array}$ & $\$ 1,000$ & $\begin{array}{l}\text { Under-estimate } \\
\text { Correct } \\
\text { Over-estimate } \\
\text { Chi-Square Test }\end{array}$ & $\begin{array}{c}34.3 \% \\
60.0 \% \\
5.7 \% \\
30.97 * * *\end{array}$ & $\begin{array}{r}24 \\
42 \\
4\end{array}$ & $\begin{array}{l}10.4 \% \\
68.8 \% \\
20.8 \% \\
44.91^{* * *}\end{array}$ & $\begin{array}{r}8 \\
53 \\
16\end{array}$ & $\begin{array}{l}7.5 \% \\
80.0 \% \\
12.5 \% \\
78.70^{* * *}\end{array}$ & $\begin{array}{r}6 \\
64 \\
10\end{array}$ & $\begin{array}{l}16.7 \% \\
70.0 \% \\
13.2 \%\end{array}$ & $\begin{array}{r}38 \\
159 \\
30\end{array}$ & $138.09 * * *$ \\
\hline All Nines & & $\begin{array}{l}\text { Under-estimate } \\
\text { Correct } \\
\text { Over-estimate } \\
\text { Chi-Square Test }\end{array}$ & $\begin{array}{l}17.9 \% \\
42.7 \% \\
39.4 \% \\
29.88 * * *\end{array}$ & $\begin{array}{r}49 \\
117 \\
108\end{array}$ & $\begin{array}{c}5.4 \% \\
42.2 \% \\
52.4 \% \\
114.56 * * *\end{array}$ & $\begin{array}{r}17 \\
132 \\
164\end{array}$ & $\begin{array}{c}5.2 \% \\
42.2 \% \\
52.6 \% \\
113.78 * * *\end{array}$ & $\begin{array}{r}16 \\
129 \\
161\end{array}$ & $\begin{array}{r}9.2 \% \\
42.3 \% \\
48.5 \%\end{array}$ & $\begin{array}{r}82 \\
378 \\
433\end{array}$ & $239.47 * * *$ \\
\hline
\end{tabular}

Notes: This exhibit reports results from the experiment where the participant was asked to recall the exact price difference between the two listed properties. The column "Digit $=1$ " results are from experimental trials where the left-most digit changed. The column "Digit $=2$ " provides results from the experiments where the second to the left-most digit changed, and so forth. "Nines $=3$ " refers to the list price that ends with three nines (999). "Nines $=2$ " references trials where the just below price ended in 990 , and so forth.

* Significance at $90 \%$.

** Significance at $95 \%$.

*** Significance at $99 \%$. 
five times the rate at which they under-estimated the difference $(9.2 \%$ under-estimated vs. $48.5 \%$ over-estimated). Alternatively stated, participants, on average, recall the just below priced homes as being priced much further below the actual price. This finding is consistent with the psychological literature supporting the implementation of just below pricing strategies.

In terms of trend, as the true price difference increases, participants are most likely to over-estimate the actual difference in prices between the two strategies. Moreover, one of the 12 paired pricing cells stands out as substantially different from the others. Specifically, when the left-most digit changes based on the price pair $\$ 200,000$ vs. $\$ 199,000$ (Digit $=1$; Nines $=3$ ), only $5.7 \%$ of participants over-estimate the price difference, whereas $34.3 \%$ of participants under-estimate the price difference. This underestimation phenomenon occurs at a rate more than three $(34.3 \%$ vs. $10.4 \%)$ and $4(34.3 \%$ vs. $7.5 \%)$ times higher than in the second and third left-most digit price pairs. ${ }^{15}$ In sum, the over-estimation effect associated with the prices ending in 999 and 990 suggests listing agents should prefer these two just below pricing strategies over the 900 and 000 price ending just below strategies. ${ }^{16}$

Now that the price truncation effect (which favors just below pricing strategies) of list prices has been documented and the psychological aspects of just below pricing are better understood, we turn to an examination of the benefits associated with the demand effect (which supports the use of round pricing). The most effective method to conduct this examination is to directly compare the TOM and the ultimate discount relative to listing price between homes that are listed using different pricing strategies. In recognition of the tradeoff between days on the market and price, it is also important to consider TOM in the investigation. Exhibit 3 reports the results of the hazard model with a Weibull distribution for our TOM variable. The results relate to the 9,131 transactions that correspond to the exact list price levels from Exhibit 2. The dummy variable is set to 1 when a round pricing strategy is employed (200,000, 192,000, and 190,000 in our case) and 0 when a just below strategy is employed. In all three specifications, the coefficient of the dummy variable is negative and statistically significant. This suggests that a round pricing strategy yields a shorter property marketing period even after the characteristics of the property and the degree of overpricing are considered. These findings are consistent with the "demand effect" hypothesis.

In Exhibit 4 we use the exact same list prices as in the experiment so that our experimental results can be directly compared to our transactions-based sales data. The results are again segmented by left-most, second to the left-most, and third to the leftmost digit changes. We find that rounded prices of $\$ 200,000$ are associated with a transaction price $0.97 \%$ lower than the list price and an average TOM of 1.83 months. Mean discounts for just below pricing strategies are significantly higher and stay on the market for significantly longer periods of time. As such, it is clear that the demand effect contributes to lower discounts and shorter TOM. In the second category of prices, we see a similar pattern. Mean discounts associated with rounded prices are $1.02 \%$ and TOM averages 1.49 months. These measures are significantly worse when just below pricing strategies are employed. An examination of the third left-most digit is less conclusive as sample size substantially wanes and results are mixed. While the lack of an effect is consistent with price truncation theory, it may also be attributed to the much smaller 


\begin{tabular}{|c|c|c|c|}
\hline Variable & (1) & (2) & (3) \\
\hline bath & & & $\begin{array}{l}0.0091 \\
(0.30)\end{array}$ \\
\hline halfbath & & & $\begin{array}{l}0.0272 \\
(1.05)\end{array}$ \\
\hline bedroom & & & $\begin{array}{l}0.0403 \\
(1.59)\end{array}$ \\
\hline $\ln ($ age $)$ & & & $\begin{array}{l}-0.0518^{* *} \\
(-2.39)\end{array}$ \\
\hline $\ln (s q f t)$ & & & $\begin{array}{l}-0.1104 \\
(-1.55)\end{array}$ \\
\hline dumnew & & & $\begin{array}{l}-0.4873^{* * *} \\
(-8.17)\end{array}$ \\
\hline$D O P$ & & $\begin{array}{l}0.1364^{* *} \\
(2.38)\end{array}$ & $\begin{array}{l}0.0755 \\
(1.13)\end{array}$ \\
\hline dumround & $\begin{array}{l}-0.2428^{* * *} \\
(-6.14)\end{array}$ & $\begin{array}{l}-0.2467^{* * *} \\
(-6.23)\end{array}$ & $\begin{array}{l}-0.2162^{* * *} \\
(-5.43)\end{array}$ \\
\hline Constant & $\begin{array}{l}-3.3961^{* * *} \\
(-76.98) \\
\end{array}$ & $\begin{array}{l}-3.4087^{* * *} \\
(-76.63) \\
\end{array}$ & $\begin{array}{l}-2.5722^{* * *} \\
(-5.50) \\
\end{array}$ \\
\hline \multicolumn{4}{|c|}{$\begin{array}{l}\text { Notes: This exhibit reports the coefficients and their respective z-stat values (in parentheses) from ou } \\
\text { Weibull distribution hazard model. TOM is the dependent variable. The number of observations is } 9,131 \text {. } \\
\text { * Significance at } 90 \% \text {. } \\
\text { * Significance at } 95 \% \text {. } \\
\text { ** Significance at } 99 \% \text {. }\end{array}$} \\
\hline
\end{tabular}

sample size. Moreover, when the TOM of the $\$ 200,000$ listing price (1.83) was compared with the TOMs of the $\$ 190,000$ and $\$ 192,000$ listing prices, the TOM for the $\$ 200,000$ price is higher with statistical significance, while the TOMs for $\$ 190,000$ and $\$ 192,000$ prices are statistically indistinguishable. When the mean discounts for the $\$ 200,000$, $\$ 190,000$, and $\$ 192,000$ listing prices are compared, we find them to be statistically indifferent. Similarly, the TOMs for the just below $\$ 200,000$ listings $(\$ 199,000$ through $\$ 199,999)$ are higher than the TOMs for the just below $\$ 190,000$ and $\$ 192,000$ listings (\$189,000 through $\$ 189,999$ and $\$ 191,000$ through $\$ 191,999$, respectively) with statistical significance. Finally, the discount associated with the just below $\$ 200,000$ and $\$ 190,000$ listings is higher than the discount on the just below $\$ 192,000$ listings with statistical significance.

So far, our results support the psychological benefits associated with just below priced homes and the demand effect benefits associated with round pricing. However, it is not yet clear which pricing strategy yields a greater net benefit for sellers. While round priced homes yield lower discount and shorter TOM, it is possible that the just below pricing strategy allows sellers to initially set a higher listing price relative to the value of their home that may compensate for the benefits of the round pricing strategy. In order to examine the net benefits of just below and rounded priced homes, we conduct an analysis that considers price discount, TOM, and the initial degree of overpricing. By employing equations (1), (2), and (3), we are able to determine which pricing strategy yields the 
Exhibit 4. First, Second, and Third Left-Most Digit Effects for the Full Sample

\begin{tabular}{|c|c|c|c|c|c|c|}
\hline Position & Obs. & $\begin{array}{l}\text { Median } \\
\text { Discount }\end{array}$ & $\begin{array}{l}\text { Mean } \\
\text { Discount }\end{array}$ & $\begin{array}{l}\text { Min. } \\
\text { Discount }\end{array}$ & $\begin{array}{l}\text { Max. } \\
\text { Discount }\end{array}$ & $\begin{array}{l}\text { TOM } \\
\text { (Mon) }\end{array}$ \\
\hline \multicolumn{7}{|c|}{ First Left-most Digit Effect } \\
\hline$\$ 200,000$ & 729 & $0.00 \%$ & $0.97 \%$ & $-17.50 \%$ & $20.00 \%$ & 1.83 \\
\hline$\$ 199,999$ & 128 & $0.37 \%$ & $1.35 \%$ & $-6.60 \%$ & $15.00 \%$ & $2.93^{* * *}$ \\
\hline$\$ 199,990$ & 24 & $0.00 \%$ & $0.09 \%$ & $-4.27 \%$ & $5.00 \%$ & 2.41 \\
\hline$\$ 199,900$ & 2920 & $0.00 \%$ & $1.26 \% * * *$ & $-15.81 \%$ & $19.96 \%$ & $2.30 * * *$ \\
\hline$\$ 199,000$ & 835 & $0.00 \%$ & $1.97 \% * * *$ & $-17.84 \%$ & $19.60 \%$ & $2.51 * *$ \\
\hline \multicolumn{7}{|c|}{ Second Left-most Digit Effect } \\
\hline$\$ 190,000$ & 743 & $0.00 \%$ & $1.02 \%$ & $-19.14 \%$ & $19.47 \%$ & 1.49 \\
\hline$\$ 189,999$ & 39 & $0.53 \%$ & $1.71 \%$ & $-2.63 \%$ & $10.53 \%$ & $2.73^{* * *}$ \\
\hline$\$ 189,990$ & 19 & $0.52 \%$ & $1.33 \%$ & $-5.17 \%$ & $10.78 \%$ & 1.29 \\
\hline$\$ 189,900$ & 2605 & $0.00 \%$ & $1.35 \% * * *$ & $-19.27 \%$ & $19.48 \%$ & $1.98^{* * *}$ \\
\hline$\$ 189,000$ & 632 & $1.06 \%$ & $2.00 \% * * *$ & $-14.81 \%$ & $17.99 \%$ & $2.32 * * *$ \\
\hline \multicolumn{7}{|c|}{ Third Left-most Digit Effect } \\
\hline$\$ 192,000$ & 129 & $0.00 \%$ & $0.61 \%$ & $-13.30 \%$ & $14.06 \%$ & 1.48 \\
\hline$\$ 191,999$ & 0 & & & & & \\
\hline$\$ 191,990$ & 0 & & & & & \\
\hline$\$ 191,900$ & 121 & $0.00 \%$ & $-0.32 \% * *$ & $-19.44 \%$ & $10.11 \%$ & 1.76 \\
\hline$\$ 191,000$ & 26 & $0.00 \%$ & $0.52 \%$ & $-7.38 \%$ & $8.38 \%$ & $1.95 *$ \\
\hline
\end{tabular}

Notes: This exhibit reports discount percentages (transaction price relative to list price) and TOM for the three price cluster groups associated with each digit change.

* Significance at $90 \%$.

* Significance at $95 \%$.

$* * *$ Significance at $99 \%$.

highest transaction price relative to the true value of the house (as opposed to the listing price) while considering the TOM. The strategy that yields a higher value-adjusted selling price is the preferred pricing strategy.

Exhibit 5 shows that when the (first) left-most digit is considered, there is no statistically significant difference in the degree of over pricing (DOP) and transaction premium between the round priced homes and the home priced with a 999, 990, or 900. However, just below priced homes that are priced at $\$ 199,000$ are associated with a significantly higher DOP and yield a higher transaction premium relative to rounded priced homes. The premium difference of $2.97 \%$ also carries an economic significance that translates into nearly $\$ 6,000$ of final price premium relative to the estimated home value. When the second left-most digit is considered, just below pricing consistently yields better results than the rounded priced homes and carries both statistical and economic significance. In this category, the premium associated with just below pricing exceeds rounded priced homes by $2.2 \%$ to $3.1 \%$. The results associated with the third left-most digit also display some advantage to the just below pricing, but these results are difficult to interpret due to a very small (or in some cases non-existing) sample size. Aggregating the results of changes in the first, second, and third left-most digit solidifies our previous findings and points to a clear advantage of the just below strategy compared with the round pricing strategy. 
Exhibit 5. First, Second, and Third Left-Most Digit Effects for the Full Sample

\begin{tabular}{|c|c|c|c|}
\hline Position & Obs. & $\begin{array}{l}\text { Median } \\
\text { DOP } \\
\end{array}$ & $\begin{array}{l}\text { Median Transaction } \\
\text { Premium } \\
\end{array}$ \\
\hline \multicolumn{4}{|l|}{ First Left-most Digit Effect } \\
\hline$\$ 200,000$ & 344 & $4.59 \%$ & $3.20 \%$ \\
\hline$\$ 199,999$ & 63 & $4.11 \%$ & $3.30 \%$ \\
\hline$\$ 199,990$ & 12 & $3.82 \%$ & $1.21 \%$ \\
\hline$\$ 199,900$ & 1374 & $4.36 \%$ & $3.29 \%$ \\
\hline$\$ 199,000$ & 379 & $8.09 \% * * *$ & $6.17 \% * * *$ \\
\hline \multicolumn{4}{|c|}{ Second Left-most Digit Effect } \\
\hline$\$ 190,000$ & 332 & $2.43 \%$ & $1.74 \%$ \\
\hline$\$ 189,999$ & 22 & $4.38 \% * *$ & $3.95 \% *$ \\
\hline$\$ 189,990$ & 9 & $6.98 \% *$ & $4.80 \% *$ \\
\hline$\$ 189,900$ & 1210 & $5.64 \% * * *$ & $4.22 \% * * *$ \\
\hline$\$ 189,000$ & 297 & $7.01 \% * * *$ & $4.65 \% * * *$ \\
\hline \multicolumn{4}{|l|}{ Third Left-most Digit Effect } \\
\hline$\$ 192,000$ & 129 & $2.19 \%$ & $1.13 \%$ \\
\hline$\$ 191,999$ & 0 & & \\
\hline$\$ 191,990$ & 0 & & \\
\hline$\$ 191,900$ & 40 & $5.89 \% *$ & $4.39 \% *$ \\
\hline$\$ 191,000$ & 26 & $-1.01 \%$ & $-0.49 \%$ \\
\hline \multicolumn{4}{|c|}{ First, Second, \& Third Left-most Digit Effect } \\
\hline$\$ x x x, 000$ & 805 & $3.31 \%$ & $2.26 \%$ \\
\hline$\$ x x x, 999$ & 85 & $4.18 \% *$ & $3.47 \% *$ \\
\hline$\$ x x x, 990$ & 21 & $4.17 \%$ & $2.75 \%$ \\
\hline$\$ x x x, 900$ & 2624 & $4.98 \% * * *$ & $3.74 \% * * *$ \\
\hline$\$ x x x, 000$ & 702 & $7.30 \% * * *$ & $5.28 \% * * *$ \\
\hline \multicolumn{4}{|c|}{$\begin{array}{l}\text { Notes: This exhibit reports the degree of overpricing (listing price relative to estimated value) and the final } \\
\text { transaction premium (transaction price relative to estimated value) percentages for the three price cluster } \\
\text { groups associated with each digit change. } \\
\text { * Significance at } 90 \% \text {. }\end{array}$} \\
\hline
\end{tabular}

In sum, the psychological effects linked to the just below pricing appear to dominate the demand effects that are related to the rounded pricing. Whether or not sellers are aware of the magnitude of the net benefits resulting from just below pricing, just below pricing strategies are employed $81.0 \%$ of the time.

\section{Conclusion}

We observe that residential real estate agents widely disagree on the appropriate pricing strategy to use when listing residential real estate for sale. Should prices be rounded or listed at just below round numbers (e.g., \$200,000 vs. \$199,900)? One explanation for this remaining industry uncertainly is that only four studies have ever been conducted in real estate to identify which pricing strategy dominates in terms of price and TOM. Moreover, these studies reached opposite conclusions and were published nearly a decade ago before the most recent meteoric rise and precipitous fall in home prices. 
We examine pricing strategies by incorporating the left-most digit effect into both an experimental design and when analyzing actual transactions data. An experimental design is necessary because the psychological pricing effects cannot be inferred from transactions data. All else constant, we find that homebuyers more often prefer homes priced using a just below pricing strategy. This preference allows sellers to list their home for a higher initial listing price as we observe when we empirically estimate home values. On the other hand, due to the demand effect, rounded priced homes yield shorter TOM and lower discount relative to listing price. The net effect of the benefits from the two pricing strategies reveals that just below pricing is the superior pricing strategy since it yields a higher final transaction price relative to the home value when controlling for TOM. These findings suggest that sellers' ability to set higher listing prices for properties using a just below pricing strategy outweighs the lower discount and shorter TOM associated with similar rounded priced strategy homes.

The results found in the price ranges we consider in this study cannot be generalized to apply to all price ranges. For example, it is entirely possible that higher priced homes, which presumably have an entirely different clientele of buyers and sellers who may or may not differ in their level of sophistication, may or may not be susceptible to these same psychological conditions, and/or certainly not to the same extent. As such, we leave future examination of the generalizability of our work to future research.

\section{Appendix}

\section{Variable Definitions}

sqft Living area of the house measured in square feet.

age Age of the house measured in years.

bedroom Number of bedrooms in the house.

bath Number of bathrooms in the house.

balfbath Number of half bathrooms in the house.

dumyear_ $i$ Dummy variable indicating the year during which the transaction took place; $i$ can take an integer value between 1994 and 2011 .

dumnew Dummy variable indicating whether the property is new or existing structure.

dumround Dummy variable indicating whether the pricing strategy employed is a round or just below strategy.

\section{Endnotes}

${ }^{1}$ Given that real estate agents regularly attend seminars and training sessions designed to increase exposure for their listings, this benefit should be self-evident.

2 If the prices are sorted from low to high, then a $\$ 200,000$ listing would be the first to appear in the search range of $\$ 200,000-\$ 250,000$ and the last to appear in the $\$ 150,000$ $\$ 200,000$ search. Alternatively, if the prices are sorted from high to low, then a $\$ 200,000$ listing would be the last to appear in the search range of $\$ 200,000-\$ 250,000$, but the first 
to appear in the $\$ 150,000-\$ 200,000$ search. Either way, a $\$ 200,000$ listing gets far more exposure than a just below priced home, and at times, appears as the very first home.

3 With interest rates near zero and time-on-the-market being so brief, we ignore the time value of money.

${ }^{4}$ Only $3 \%$ of prices end in a " $1,2,3,4,6,7$, or 8 ." The remaining $30 \%$ of observations end in a " 5 ."

5 In Australia, coins smaller than 5 cents have not been used since 1992, yet still today, prices continue to be listed in fractions (such as \$3.98) for which proper change cannot be given.

${ }^{6}$ In a hedonic methodology, this same goal is accomplished by fully and properly specifying the regression.

${ }^{7}$ Homebuyers were restricted to the state of Virginia to roughly match the geographic area where the transactions data were collected.

8 The four just below prices we selected ended in values of 999, 990, 900, and 000.

9 For example, if a particular house was on the market for 69 days before it sold, TOM will be assigned a value of $69 / 365^{*} 12=2.27$.

${ }^{10}$ We thank an anonymous referee for suggesting the employment of this type of hazard model to better investigate the TOM associated with each pricing strategy.

11 We define the variables in the Appendix.

${ }^{12}$ It is unclear whether real estate agents use the 900 and 000 ending prices for strategic versus convenience reasons. But, it is clear that they are better off for having done so, at least from a psychological pricing standpoint. As pointed out by a reviewer, it is interesting to convey the idea that the benefit (cost) to the agent of listing at $\$ 900$ more (or $\$ 100$ less) is only $\$ 27$ (or \$3) at a 3\% commission rate, but $\$ 827$ or (\$97) to the seller.

13 These sample list prices correspond to the left-most digit change and therefore represent the correct figures for just the first column.

14 This is an astounding number and points to the quality of the sample.

15 Thomas and Morwitz (2005) also find that the misperception in price differences only occurs when the left-most digit changes.

16 This statement is true only when isolating the misperceived pricing difference effect. It is not an overall recommendation after considering the entire impact of just below pricing versus the demand effect.

\section{References}

Allen, M. and W. Dare. The Effects of Charm Listing Prices on House Transaction Prices. Real Estate Economics, 2004, 32:4, 695-713.

- Charm Pricing as a Signal of Listing Price Precision. Journal of Housing Research, 2006, $15: 2,113-27$.

Bhattacharya, U., C. Holden, and S. Jacobsen. Penny Wise, Dollar Foolish: Buy-Sell Imbalances On and Around Round Numbers. Management Science, 2012, 58:2, 413-31.

Dehaene, S. The Number Sense. New York, NY: Oxford University Press, 1997.

Gendall, P., J. Holdershaw, and R. Garland. The Effect of Odd Pricing on Demand. European Journal of Marketing, 1997, 31:11/12, 799-813.

Holdershaw, J., P. Gendall, and R. Garland. The Widespread Use of Odd Pricing in the Retail Sector. Marketing Bulletin, 1997, 8, 53-8. 
Palmon, O., B. Smith, and B. Sopranzetti. Clustering in Real Estate Prices: Determinants and Consequences. Journal of Real Estate Research, 2004, 26:2, 115-36.

Salter, S.P., K.H. Johnson, and W.P. Spurlin. Off-Dollar Pricing, Residential Property Price and Marketing Time. Journal of Housing Research, 2007, 16:1, 33-46.

Schindler, R. and T. Kibarian. Increased Consumer Sales Response Through Use of 99-Ending Prices. Journal of Retailing, 1996, 72:2, 187-200.

Seiler, M. The Effect of Perceived Lender Characteristics and Market Conditions on Strategic Mortgage Defaults. Journal of Real Estate Finance and Economics, 2014a, 48:2, 256-70.

- Understanding the Prevalence and Implications of Homeowner Money Illusion. Journal of Behavioral and Experimental Finance, 2014b, 1:1, 74-84.

—. Do as I Say, Not as I Do: The Role of Advice versus Actions in the Decision to Strategically Default. Journal of Real Estate Research, 2015, 37:2, 191-216.

Seiler, M., M. Lane, and D. Harrison. Mimetic Herding Behavior and the Decision to Strategically Default. Journal of Real Estate Finance and Economics, 2014, 49:4, 621-53.

Seiler, M., P. Madhavan, and M. Liechty. Toward an Understanding of Real Estate Homebuyer Internet Search Behavior: An Application of Ocular Tracking Technology. Journal of Real Estate Research, 2012, 34:2, 211-41.

Seiler, M. and V. Seiler. Mitigating Investor Risk-Seeking Behavior in a Down Real Estate Market. Journal of Behavioral Finance, 2010, 11:3, 161-67.

Seiler, M., V. Seiler, D. Harrison, and M. Lane. Familiarity Bias and Perceived Future Home Price Movements. Journal of Behavioral Finance, 2013, 14:1, 9-24.

Seiler, M., V. Seiler, and M. Lane. Mental Accounting and False Reference Points in Real Estate Investment Decision Making. Journal of Behavioral Finance, 2012, 13:1, 17-26.

Seiler, M., V. Seiler, M. Lane, and D. Harrison. Fear, Shame, and Guilt: Economic and Behavioral Motivations for Strategic Default. Real Estate Economics, 2012, 40:S1, 199-233.

Stiving, M. and R. Winer. An Empirical Analysis of Price Endings with Scanner Data. Journal of Consumer Research, 1997, 24, 57-68.

Thomas, M. and V. Morwitz. Penny Wise and Pound Foolish: The Left-Digit Effect in Price Cognition. Journal of Consumer Research, 2005, 32, 54-64.

We would like to thank the Virginia Association of Realtors ${ }^{\circledR}$ (VAR) for access to their sample of homeowners for the experimental component of this study. We specifically acknowledge the special assistance of Stacey Ricks at VAR. We would also like to thank REIN in Hampton Roads, Virginia for providing transactions data for the empirical aspect of this study.

Eli Beracha, Florida International University, Miami, FL 33131 or eberacha@fiu.edu. Michael J. Seiler, The College of William \& Mary, Williamsburg, VA 23187-8795 or Michael.Seiler@mason.wm.edu. 
